\title{
Computational study of the stereoselectivity profiles of the Diels-Alder cycloaddition reactions of cyclopentadiene and butadiene with cyclopropenes
}

\author{
Veejendra K. Yadav* \\ Department of Chemistry, Indian Institute of Technology Kanpur, Kanpur 208016, India \\ vijendra@iitk.ac.in
}

\begin{abstract}
The endo and exo stereoselectivities of the Diels-Alder (DA) cycloaddition reactions of 3,3disubstituted cyclopropenes with butadiene and cyclopentadiene, the latter for the first time, were investigated by means of density functional and quantum chemical calculations for a comparison. To establish distinction between the selectivites, activation free energies were systematically estimated in the gas phase and also under solvent effects. The differential activation free energies clearly predict exclusive endo configuration of the products formed from the reaction of the unsubstituted cyclopropene with butadiene and cyclopentadiene. However, the results were found to be markedly different for the substituted cyclopropenes from the available experimental selectivities. It was also discovered that butadiene and cyclopentadiene are markedly different in their respective stereospecific product yields, nevertheless the difference between the two is only a methylene group. The failure of the differential activation free energy approach to predict the experimental stereoselectivities of the DA reactions of several perhalocyclopropenes with cyclopentadiene is probably due to yet insufficient development of the various theoretical models dealing with the endo and exo DA preferences.
\end{abstract}

\section{INTRODUCTION}

The experimental endo and exo stereoselectivities of the DA cycloaddition reactions of cyclopentadiene with cyclopropene 1a, cyclopropenone acetal $\mathbf{1 b}$, perfluorocyclopropene 1c, 1,2-dichloro-3,3-difluorocyclopropene $\mathbf{1 d}$ and 1,2-dibromo-3,3-difluorocyclopropene $1 \mathbf{e}$ are given in Scheme 1. While $1 \mathbf{a}\left(\mathrm{CH}_{2} \mathrm{Cl}_{2}, 0{ }^{\circ} \mathrm{C}\right)^{1}$ and $\mathbf{1 c}\left(\mathrm{CDCl}_{3}\right.$, $\left.25^{\circ} \mathrm{C}\right)^{3,4}$ form the endo adduct exclusively, $\mathbf{1 d}$ and $\mathbf{1 e}$ generate only the exo adduct $\left(\mathrm{CCl}_{4}, 0^{\circ} \mathrm{C}\right)^{3}$ and $\mathbf{1} \mathbf{b}^{2}$ exhibits 
no selectivity for furnishing an equal mixture of both the adducts at $25{ }^{\circ} \mathrm{C}$ under no solvent conditions. The corresponding reactions of butadiene with the cyclopropenes $1 \mathbf{a},{ }^{1,6} \mathbf{1} \mathbf{b},{ }^{2} \mathbf{1} c^{5} \mathbf{1} \mathbf{d}^{7}$ and $\mathbf{1} \mathbf{e}^{7}$ are also reported in the literature. The stereochemistry of the reaction of $\mathbf{1 c}$ has not been firmly secured. Among the rest, $1 \mathbf{a}$ adds endo and the others exo exclusively.

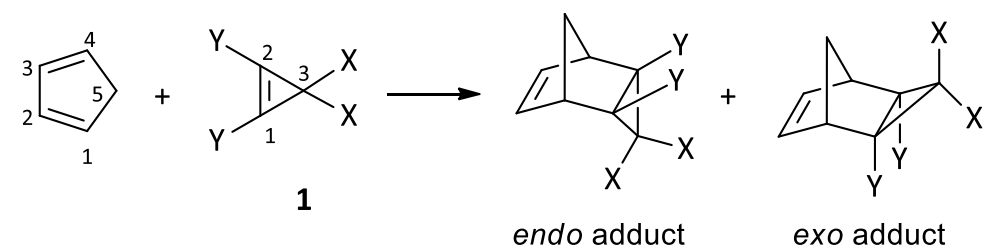

$$
\begin{aligned}
& \text { 1a, } X=\mathrm{H}, \mathrm{Y}=\mathrm{H} ; \text { endo:exo }=100: 0 \\
& \text { 1b, } X=-\mathrm{O}\left(\mathrm{CH}_{2}\right)_{3} \mathrm{O}-, \mathrm{Y}=\mathrm{H} ; \text { endo:exo }=50: 50 \\
& \text { 1c }, X=\mathrm{F}, \mathrm{Y}=\mathrm{F} ; \text { endo:exo }=100: 0 \\
& \text { 1d, } \mathrm{X}=\mathrm{F}, \mathrm{Y}=\mathrm{Cl} ; \text { endo:exo }=0: 100 \\
& \text { 1e, } \mathrm{X}=\mathrm{F}, \mathrm{Y}=\mathrm{Br} ; \text { endo:exo }=0: 100
\end{aligned}
$$

Scheme 1. The experimental endo and exo selectivities of the DA cycloaddition reactions of the cyclopropenes 1a-e with cyclopentadiene

The stereoselectivities of the DA reactions of unsubstituted and substituted butadienes with unsubstituted, 3substituted and 3,3-disubstitiued cyclopropenes have been the subject of several computational investigations in the recent past. For instance,

(a) Jursic has studied the reaction of cyclopropene with butadiene at the B3LYP/6-31G(d) density functional level and concluded that the endo transition state (TS) structure was $2.0 \mathrm{kcal} / \mathrm{mol}$ lower in energy than the corresponding exo TS structure due to the Secondary Orbital Interactions (SOI) between the methylene hydrogen of cyclopropene and the developing $\pi$-bond in butadiene. ${ }^{8}$ 
(b) Fujimoto and co-workers have studied the reaction of cyclopropene with a range of substituted butadienes and concluded that the electrostatic interactions between the reactants also contributed to the stereoselectivity along with the SOI. ${ }^{9}$

(c) Poirier and Burnell have investigated the reactions of cyclopropene and 3$\mathrm{BH}_{2} / \mathrm{CH}_{3} / \mathrm{SiH}_{3} / \mathrm{NH}_{2} / \mathrm{PH}_{2} / \mathrm{OH} / \mathrm{SH} / \mathrm{F} / \mathrm{Cl}$ substituted cyclopropenes with butadiene at the B3LYP/6$31++G(d) / / H F / 6-31++G(d)$ level and concluded that there was no contribution of the SOI to the stereoselectivity. ${ }^{10}$

(d) Gosse and Poirier have studied the reaction of butadiene with 3,3-disubstituted cyclopropenes (the substituents were $\mathrm{CH}_{3}, \mathrm{SiH}_{3}, \mathrm{NH}_{2}, \mathrm{PH}_{2}, \mathrm{OH}, \mathrm{SH}, \mathrm{F}$ and $\mathrm{Cl}$ ) at the $\mathrm{B} 3 \mathrm{LYP} / 6-31++\mathrm{G}(\mathrm{d})$ level and observed that the exo TS structure was consistently favored over the corresponding endo TS structure. ${ }^{11}$

(e) Lewandowski and Houk have very recently studied the reactions of cyclopropene, 3-substituted cyclopropenes and 3,3-disubstituted cyclopropenes with butadiene at the M06-2X/6-31+G(d) density functional level and suggested that factors such as hyperconjugation, electrostatic and steric effects also contributed along with the SOI to the stereoselectivity. ${ }^{12}$ This study was inspired by the experimental selectivities of the DA reactions of the cyclopropenes 1a-e with cyclopentadiene. However, cyclopentadiene was never used in the calculations.

A similar investigation of the DA reactions of cyclopentadiene with 3,3-disubstituted and also 1,2,3,3tetrasubstituted cyclopropenes has not been reported till date. We, therefore, have calculated the activation free energies $\left(\Delta G^{\ddagger}\right)$ of the reactions of both cyclopentadiene and butadiene with the cyclopropenes 1a-e to: (a) compare the stereochemical features while the difference is that of only a methylene group and (b) assess how well the stereoselectivities calculated for cyclopentadiene corresponded with the experimental stereoselectivities. 
We demonstrate herein that (a) the stereochemical results obtained for the reactions of cyclopropenes with butadiene are significantly different from those with cyclopentadiene and (b) the differential activation energy does not always corroborate with the experimental selectivity.

\section{COMPUTATIONAL METHODS}

All the structures, geometry optimizations and TS structure searches were carried out using the global hybrid meta-GGA M06-2X density functional and 6-31+G(d) basis set. ${ }^{13}$ Quantum chemical calculations at the second order perturbation theory MP2/6-31G(d) level ${ }^{14}$ were carried out for comparison. The optimized structures were verified as minima or first order saddle points on their potential energy surfaces by harmonic vibrational frequency analysis. Calculations at the gold standard CCSD/6-31G(d)//MP2/6-31G(d) level (full optimization) and $\operatorname{CCSD}(\mathrm{T}) / 6-31 \mathrm{G}(\mathrm{d}) / / \mathrm{MP} 2 / 6-31 \mathrm{G}(\mathrm{d})$ level (single point calculation) were also carried out to compare the results obtained at other levels of theory. The solvation effects of dichloromethane $\left(\mathrm{CH}_{2} \mathrm{Cl}_{2}\right)$, chloroform $\left(\mathrm{CHCl}_{3}\right)$ and carbon tetrachloride $\left(\mathrm{CCl}_{4}\right)$ were estimated using the Conductor Polarized Continuum Model (CPCM). ${ }^{15}$ Calculations were carried out using the Gaussian 09 suite of programs. ${ }^{16}$

\section{RESULTS AND DISCUSSION}

The activation free energies of the endo and exo TS structures for the reactions of the cyclopropenes 1a-1e with cyclopentadiene are given in Table 1 . While the cyclopropene $1 \mathrm{a}$ is predicted to undergo exclusive endo addition, the perfluorocyclopropene $\mathbf{1} \mathbf{c}$ is predicted for predominantly exo addition. In contrast, the acetal $\mathbf{1 b}$ is predicted to furnish an equal mixture of the two products. Like 1b, both 1,2-dichloro-3,3-difluorocyclopropene 1d and 1,2-dibromo-3,3-difluorocyclopropene $\mathbf{1 e}$ are also predicted to form mixtures, but predominating in the endo product. All the reactions are highly exergonic, ranging from 17-31 kcal/mol. While the predictions for 1a 
and $\mathbf{1 b}$ corroborate well with the experiments, they contrast the observed exclusive endo selectivity for $\mathbf{1 c}$ and exo selectivities for both $\mathbf{1 d}$ and $\mathbf{1 e}$.

Table 1. Activation free energies $\left(\Delta G^{\ddagger}\right)$ and enthalpy changes $\left(\Delta G_{\text {endo/exo }}\right), \mathrm{kcal} / \mathrm{mol}$, for the gas phase DA reactions of 1a-e with cyclopentadiene and butadiene at the M06-2X/6-31+G(d) level and $298.15 \mathrm{~K}$

\begin{tabular}{|c|c|c|c|c|c|c|c|}
\hline \multirow{2}{*}{ cyclopropene } & \multicolumn{4}{|c|}{ reaction with cyclopentadiene } & \multicolumn{3}{c|}{ reaction with butadiene } \\
\cline { 2 - 8 } & $\Delta G^{\ddagger}{ }_{\text {endo }}$ & $\Delta G_{\text {exo }}^{\ddagger}$ & $\mathrm{k}_{\text {endo }}: \mathrm{k}_{\text {exo }}$ & $\Delta \mathrm{G}_{\text {endo/exo }}$ & $\Delta G_{\text {endo }}^{\ddagger}$ & $\Delta G_{\text {exo }}^{\ddagger}$ & $\mathrm{k}_{\text {endo: }}: \mathrm{k}_{\text {exo }}$ \\
\hline 1a & 20.84 & 24.98 & $>99: 1$ & $-29.7 /-31.4$ & 20.64 & 23.20 & $98: 2$ \\
\hline 1b & 27.07 & 27.22 & $55: 45$ & $-19.4 /-24.2$ & 26.27 & 23.21 & $1: 99$ \\
\hline 1c & 27.87 & 25.56 & $<2: 98$ & $-21.6 /-26.7$ & 28.97 & 26.41 & $2: 98$ \\
\hline 1d & 26.59 & 26.85 & $60: 40$ & $-17.6 /-21.8$ & 28.62 & 26.88 & $5: 95$ \\
\hline 1e & 20.26 & 21.19 & $80: 20$ & $-23.2 /-28.0$ & 23.76 & 21.96 & $5: 95$ \\
\hline
\end{tabular}

The TS structure data for the corresponding reactions with butadiene, also given in Table 1, allows a comparison with the data for the reactions with cyclopentadiene. While the reaction of $1 \mathrm{a}$ with butadiene is exclusively endo, like the reaction with cyclopentadiene, the cyclopropenes $\mathbf{1} \mathbf{b}$-e are predicted for predominant to exclusive exo selectivities. The exclusive exo selectivity predicted for the reaction of $\mathbf{1} \mathbf{b}$ with butadiene contrasts the dismal selectivity with cyclopentadiene. Also, in contrast to the predominant exo selectivities for the reactions of $\mathbf{1 d}$ and $\mathbf{1 e}$ with butadiene, the corresponding reactions with cyclopentadiene are predicted to generate mixtures predominating in the endo products.

It is clear from the above discussion that the stereoselectivity features discerned for the DA reactions of the cyclopropenes 1a-e with butadiene are generally different from those with cyclopentadiene. This difference underlines the contribution, steric and/or electrostatic, of the additional methylene group in cyclopentadiene. 
Question arises as to why at all the TS approach failed at predicting the experimental exclusive endo selectivity for $\mathbf{1 c}$ and also the exo selectivities for $\mathbf{1 d}$ and $\mathbf{1 e}$ in their reactions with cyclopentadiene. Is the global hybrid meta-GGA M06-2X density functional inappropriate at handling halogen-containing molecules? ${ }^{17}$ We chose to carry out the above calculations using the MP2/6-31G(d) wave functional for comparison. The results are collected in Table 2. A comparison of the data in the Tables 1 and 2 readily reveals that both the levels of calculation are qualitatively very similar. The exclusive endo selectivity of $\mathbf{1 c}$ and the exo selectivities of $\mathbf{1 d}$ and 1e remain, therefore, unexplained.

Table 2. Activation free energies $\left(\Delta G^{\ddagger}\right)$ and enthalpy changes $\left(\Delta G_{\text {endo/exo }}\right), \mathrm{kcal} / \mathrm{mol}$, for the gas phase DA reactions of 1a-e with cyclopentadiene calculated at the MP2/6-31G(d) level and $298.15 \mathrm{~K}$

\begin{tabular}{|c|c|c|c|c|c|}
\hline cycopropene & $\Delta G^{\ddagger}{ }_{\text {endo }}$ & $\Delta G_{\text {exo }}^{\ddagger}$ & $k_{\text {endo }}: k_{\text {exo }}$ & $\Delta \mathrm{G}_{\text {endo }}$ & $\Delta \mathrm{G}_{\text {exo }}$ \\
\hline 1a & 15.94 & 20.44 & $>99: 1$ & -34.8 & -36.5 \\
\hline 1b & 19.71 & 19.86 & $56: 44$ & -25.4 & -30.4 \\
\hline 1c & 21.59 & 19.62 & $4: 96$ & -25.0 & -30.7 \\
\hline 1d & 18.39 & 18.82 & $68: 32$ & -23.8 & -28.7 \\
\hline 1e & 13.78 & 14.36 & $73: 27$ & -28.8 & -34.0 \\
\hline
\end{tabular}

Table 3. Activation energies $\left(\Delta E^{\ddagger}\right), \mathrm{kcal} / \mathrm{mol}$, for the gas phase DA reactions of $1 \mathrm{a}-\mathbf{e}$ with cyclopentadiene from calculations the CCSD/6-31G(d)//MP2/6-31G(d) level and $298.15 \mathrm{~K}$

\begin{tabular}{|c|c|c|c|}
\hline cycopropene & $\Delta E_{\text {endo }}^{\ddagger}$ & $\Delta E_{\text {exo }}^{\ddagger}$ & $\mathrm{k}_{\text {endo }}: \mathrm{k}_{\text {exo }}$ \\
\hline 1a & 14.16 & 18.32 & $>99: 1$ \\
\hline 1b & 18.85 & 18.67 & $46: 54$ \\
\hline 1c & 20.38 & 17.96 & $08: 92$ \\
\hline 1d & 18.54 & 18.69 & $54: 56$ \\
\hline 1e & 14.65 & 14.95 & $57: 43$ \\
\hline
\end{tabular}


We also chose to perform calculations of the ground and TS structures at CCSD/6-31G(d)//MP2/6-31G(d) level to estimate the stereoselectivity profile. The data is collected in Table 3. The stereoselectivity levels of the DA reactions of the cyclopropenes $\mathbf{1 a} \mathbf{a}$ c are much the same as at other levels of theory. However, the cyclopropenes $\mathbf{1 d}$ and $\mathbf{1 e}$ are predicted for near no selectivity which is against the experimental results. The results obtained from single point calculations at $\operatorname{CCSD}(\mathrm{T}) / 6-31 \mathrm{G}(\mathrm{d}) / / \mathrm{MP} 2 / 6-31 \mathrm{G}(\mathrm{d})$ level (see Table $3 \mathrm{~S}$ in SI) are very similar. Thus, the CCSD level calculations also failed at predicting the experimental stereoselectivities of the DA reactions of the cyclopropenes $\mathbf{1 c}-\mathbf{e}$.

In search of a rationale, we also considered the effect of solvents on stereoselectivity. The TS structure calculations were carried out to study the effect of $\mathrm{CH}_{2} \mathrm{Cl}_{2}$ on the reaction of $1 \mathrm{a}, \mathrm{CHCl}_{3}$ on the reaction of $1 \mathrm{c}$, and $\mathrm{CCl}_{4}$ on the reactions of $\mathbf{1 d}$ and $\mathbf{1 e}$. The corresponding activation free energies are given in Table 4 . It is to be easily seen that the overall trend, including the level of stereoselectivity, remained more or less the same as in the gas phase calculation in each instance. The solvent, therefore, does not have any controlling influence on the stereoselectivities of the DA reactions studied herein.

Table 4. Activation free energies $\left(\Delta G^{\ddagger}\right)$, kcal/mol, for the DA reactions of $1 \mathbf{a}$ in $\mathrm{CH}_{2} \mathrm{Cl}_{2}, \mathbf{1} \mathbf{c}$ in $\mathrm{CHCl}_{3}$, and $\mathbf{1 d}$ and $\mathbf{1 e}$ in $\mathrm{CCl}_{4}$ with cyclopentadiene calculated at the $\mathrm{M06}-2 \mathrm{X} / 6-31+\mathrm{G}(\mathrm{d})$ level and $298.15 \mathrm{~K}$

\begin{tabular}{|c|c|c|c|c|}
\hline cycopropene & solvent & $\Delta G_{\text {endo }}^{\ddagger}$ & $\Delta G_{\text {exo }}^{\ddagger}$ & $\mathrm{k}_{\text {endo }}: \mathrm{k}_{\text {exo }}$ \\
\hline 1a & $\mathrm{CH}_{2} \mathrm{Cl}_{2}$ & 20.43 & 24.69 & $>99: 1$ \\
\hline 1c & $\mathrm{CHCl}_{3}$ & 27.92 & 25.59 & $>2: 98$ \\
\hline 1d & $\mathrm{CCl}_{4}$ & 25.45 & 25.72 & $60: 40$ \\
\hline 1e & $\mathrm{CCl}_{4}$ & 19.28 & 20.19 & $80: 20$ \\
\hline
\end{tabular}

The preferential formation of the endo product in DA reactions has been attributed to the Secondary Orbital Interactions (SOI) between the atoms of the two reactants that are not bonded in the TS structure. ${ }^{18,19}$ The 
bonding interaction of the forming $\pi$ bond between the two internal $\mathrm{sp}^{2}$ carbons of the diene (cyclopentadiene or butadiene) and a substituent orbital on the dienophile (cyclopropene) in the endo TS structure constitutes the SOI as shown in Figure 1a for the reaction of 1a with cyclopentadiene. Such an interaction, of course, does not exist in the exo TS structure. In the present context, the endo addition of $\mathbf{1 b}$ is SOl-neutral, that of $1 \mathrm{c}$ somewhat repulsive as shown in Figure $1 b$, and those of $1 \boldsymbol{d}$ and $1 \boldsymbol{e}$ slightly, if at all, repulsive. The $\pi_{\mathrm{c}=\mathrm{c}} \rightarrow \pi^{*} \mathrm{c}=\mathrm{c}$ interactions between the two reactants leading to the formation of the two new $\sigma$ bonds constitute the primary interactions required for the DA reaction itself to take place and, as such, do not contribute to the stereoselectivity. Hyperconjugation, electrostatic and steric effects also contribute to the stereoselectivity as observed by Lewandowski and Houk. ${ }^{12}$

Among all the interactions, it is conceivable that a given interaction is more important than others for a given pair of reactants. Also, an argument applicable to a given pair of reactants need not necessarily be applicable to another pair of reactants. In the instance involving the DA reaction of a 3,3-disubstituted cyclopropene, the steric effects arising from the syn C3-substituent must necessarily be important in both the endo and exo TS structures. Further, depending on the nature of the substituent, the electrostatic interaction of the syn C3substituent in cyclopropene with the syn methylene-H of cyclopentadiene in the exo TS structure, as shown in Figure 2, must also be important. 
(a)

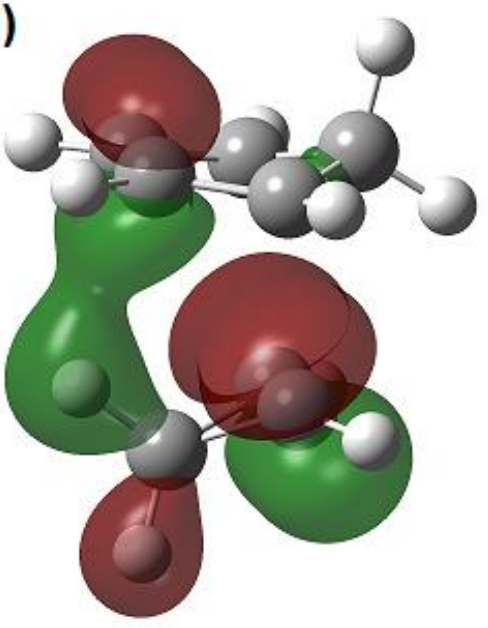

(b)

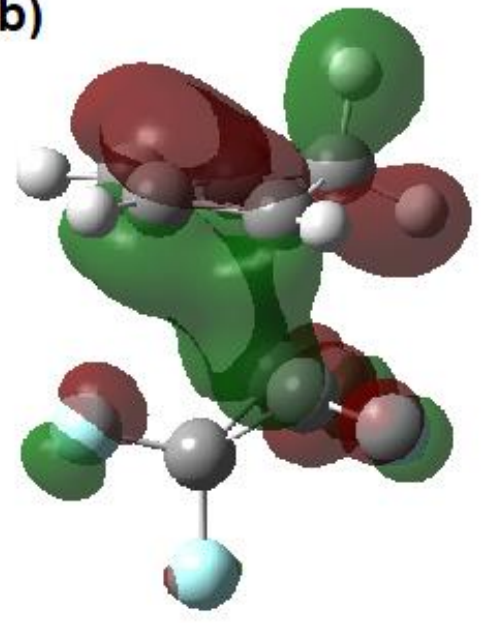

Figure 1. Molecular orbital of the TS structure for the endo DA addition of cyclopentadiene with (a) 1a showing the constructive SOI between the syn methylene $\sigma_{\mathrm{CH}}$ and the forming $\pi$ bond between the two internal $\mathrm{sp}^{2}$ carbons of cyclopentadiene and (b) 1c showing the repulsive SOI between the lone pair orbital of syn methylene- $\mathrm{F}$ and the forming $\pi$ bond
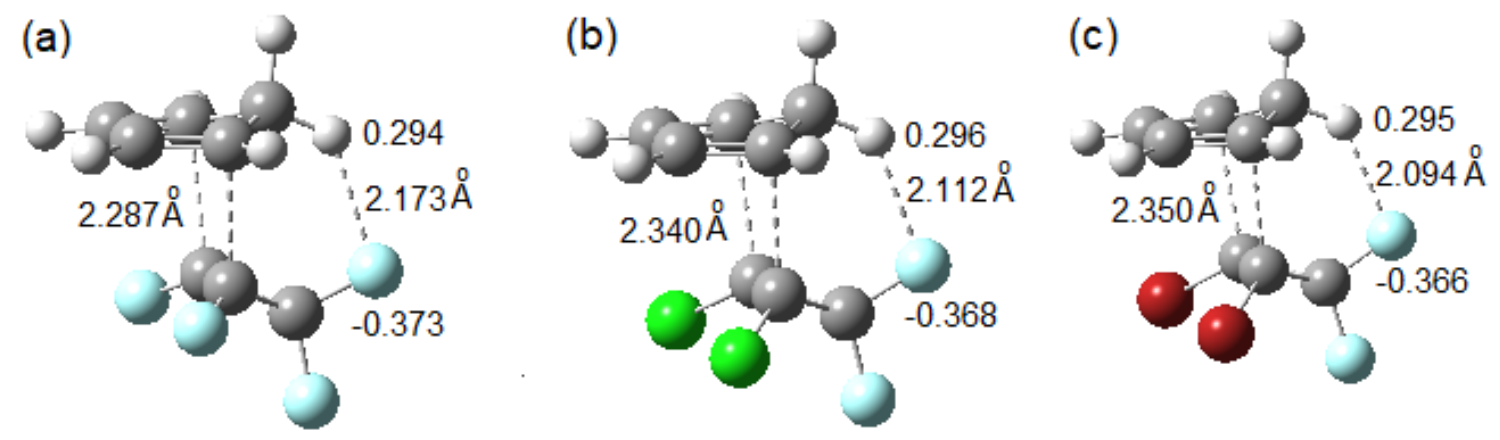

Figure 2. The electrostatic interactions between the negatively charged $F$ and the positively charged syn methylene-H in the exo TS structures for the DA reactions of (a) 1c, (b) $\mathbf{1 d}$ and (c) 1e with cyclopentadiene

It is significant to note that as the length of the forming $\sigma$ bond increases from $2.287 \AA$ to $2.340 \AA$ to $2.350 \AA$, the distance between the syn methylene-H and the syn cyclopropene-F decreases from $2.173 \AA$ to $2.112 \AA$ to 2.094 $\AA$ in (a), (b) and (c), respectively. In contrast, the NBO charges on the interacting atoms changed marginally. The electrostatic interaction, therefore, supports exo selectivity. The presence of electrostatic interactions in the exo 
TS structures together with the absence of SOI in the endo TS structures do explain the observed exo selectivities of $1 d$ and 1e. However, the similar electrostatic interaction coupled with the somewhat repulsive SOI in the endo TS structure predicts exo selectivity of $1 c$, which contradicts the experiment. An all-applicable unified rationale is therefore not available.

It is generally understood that all the possible interactions, constructive or otherwise, are ingrained in the TS structure and, hence, the differential activation free energy $\left(\Delta \Delta G^{\ddagger}\right)$ must predict well the level of stereoselectivity on further translation to the kinetic spread of products ${ }^{20}$ for irreversible processes such as the present DA reactions. The failure of $\Delta \Delta G^{\ddagger}$ in predicting the experimentally observed DA stereoselectivities of 1c-e with cyclopentadiene is bothersome. It appears that the various theoretical models dealing with the endo and exo DA preferences are not sufficiently developed even today to allow sound predictions in such (complicated) situations.

\section{CONCLUSION}

The application of differential activation free energy to the kinetic spread of the endo and exo products from the irreversible DA cycloaddition reactions of cyclopentadiene with perfluorocyclopropene 1c, 1,2-dichloro-3,3difluorocyclopropene $\mathbf{1 d}$ and 1,2-dibromo-3,3-difluorocyclopropene 1e failed at predicting the experimental stereoselectivities at different levels of theory. The TS approach favors exo selectivity against the endo observed for $1 \mathrm{c}$ and formation of mixtures, predominating in the endo isomer, in contrast to the exclusive exo selectivities observed for $\mathbf{1 d}$ and $\mathbf{1 e}$. Also, the stereoselectivities of the DA reactions of cyclopentadiene to substituted cyclopropenes are generally different from that of butadiene.

The failure of the differential activation energy at correctly predicting the experimental selectivities of the DA reactions of $\mathbf{1 c}, \mathbf{1} \mathbf{d}$ and $\mathbf{1 e}$ with cyclopentadiene leaves us to also conclude that the various theoretical models dealing with the stereoselectivities of the DA reactions are not sufficiently developed to allow sound predictions in complicated situations. 


\section{ASSOCIATED CONTENT}

\section{Supporting Information}

Cartesian coordinates of the optimized substrates, transition state structures, Gibbs' free energies and total electronic energies (PDF, 33 pages)

\section{AUTHOR INFORMATION}

\section{Corresponding Author}

vijendra@iitk.ac.in

\section{ORCID}

Veejendra Yadav: 0000-0001-8294-0677

\section{ACKNOWLEDGMENTS}

The author thanks the Department of Science \& Technology, Government of India, for financial support. The author also acknowledges allocation of time on HPC2013 series of supercomputers by the Computer Centre of IIT Kanpur.

\section{REFERENCES AND NOTES}

1. Wiberg, K. B.; Bartley, W. J. Cyclopropene. V. Some Reactions of Cyclopropene. J. Am. Chem. Soc. $1960,82,6375-6380$.

2. Boger, D. L.; Brotherton, C. E. Diels-Alder Cycloaddition Reactions of Cyclopropenone Ketals. Tetrahedron 1986, 42, 2777-2785.

3. Battiste, M. A.; Posey, R. G. J. Synthesis and fluorine NMT chemical shifts for a series of exo-3,3difluorocyclo[3.2.1.0 $0^{2,4}$ ]octyl derivatives. The Diels-Alder alternative to difluorocarbene additions. J. Fluorine Chem. 2000, 102, 285-292. 
4. Sargeant, P.B. Fluorocyclopropanes. III. 1,4-Cycloaddition Reactions of Perfluorocyclopropene and 1,2-Bis(trifluoromethyl)-3,3-difluorocyclopropene. J. Am. Chem. Soc. 1969, 91, 3061-3068.

5. Sargeant, P. B.; Krespan, C. G. Fluorocyclopropanes. II. Synthesis, Properties, and Reactions of Perfluorocyclopropene. J. Am. Chem. Soc. 1969, 91, 415-419.

6. Baldwin, J. E.; Reddy, V. P. Stereochemistry of the Diels-Alder reaction of butadiene with cyclopropene. J. Org. Chem. 1989, 54, 5264-5267.

7. Law, D. C. F.; Tobey, S. W. Diels-Alder Reactions of Tetrahalocyclopropenes. J. Am. Chem. Soc. 1968, 99, 2376-2386.

8. Jursic, B. S. A Density Functional Theory Study of Secondary Orbital Overlap in Endo Cycloaddition Reactions. An Example of a Diels-Alder Reaction between Butadiene and Cyclopropene. J. Org. Chem. $1997,62,3046-3048$.

9. Imade, M.; Hirao, H.; Omoto, K.; Fujimoto, H. Theoretical Study of Endo Selectivity in the Diels-Alder Reactions between Butadienes and Cyclopropene. J. Org. Chem. 1999, 64, 6697-6701.

10. Xidos, J. D.; Gosse, T. L.; Burke, E. D.; Poirier, R. A.; Burnell, D. J. Endo-Exo and Facial Stereoselectivity in the Diels-Alder Reactions of 3-Substituted Cyclopropenes with Butadiene. J. Am. Chem. Soc. 2001, $123,5482-5488$.

11. Gosse, T. L.; Poirier, R. A. Exo selectivity and the effect of disubstitution in the Diels-Alder reactions of butadiene with 3,3-disubstituted cyclopropenes. Can. J. Chem. 2004, 82, 1589-1596.

12. (a) Lewandowski, B. J.; Houk, K. N. Hyperconjugative, Secondary Orbital, Electrostatic, and Steric Effects on the Reactivities and Endo and Exo Stereoselectivities of Cyclopropene Diels-Alder Reactions. J. Am. Chem. Soc. 2016, 138, 16731-16736. (b) The experimental result of the DA cycloaddition reaction of 3,3-difluorocyclopropene to cyclopentadiene has not been reported in the literature as claimed in this work. 
13. Zhao, Y.; Truhlar, D. G. The M06 site of density functionals for main group thermochemistry, thermochemical kinetics, noncovalent interactions, excited states, and transition elements: Two new functionals and systematic testing of four M06-class functionals and 12 other functionals. Theor. Chem. Acc. 2008, 120, 215-241.

14. (a) Moller, C.; Plesset, M. S. Note on an Approximation Treatment for Many-Electron Systems. Phys. Rev. 1934, 46, 618-622. (b) Head-Gordon, M.; Pople, J. A.; Frisch, M. J. MP2 energy evaluation by direct methods. Chemical Physics Letters. 1988, 153, 503-506.

15. (a) Barone, V.; Cossi, M. Quantum Calculation of Molecular Energies and Energy Gradients in Solution by a Conductor Solvent Model. J. Phys. Chem. A 1998, 102, 1995-2001. (b) Cossi, M.; Rega, N.; Scalmani, G.; Barone, V. Energies, structures, and electronic properties of molecules in solution with the CPCM solvation model. J. Comput. Chem. 2003, 24, 669-681.

16. Gaussian 09, Revision B.01, Frish, M. J.; Trucks, G. W.; Schlegel, H. B.; Scuseria, G. E.; Robb, M. A.; Cheeseman, J. R.; Scalmani, G.; Barone, V.; Mennucci, B.; Petersson, G. A.; Nakatsuji, H.; Caricato, M.; Li, X.; Hratchian, H. P.; Izmaylov, A. F.; Bloino, J.; Zheng, G.; Sonnenberg, J. L.; Hada, M.; Ehara, M.; Toyota, K.; Fukuda, R.; Hasegawa, J.; Ishida, M.; Nakajima, T.; Honda, Y.; Kitao, O.; Nakai, H.; Vreven, T.; Montgomery, J. A., Jr.; Peralta, J. E.; Ogliaro, F.; Bearpark, M.; Heyd, J. J.; Brothers, E.; Kudin, K. N.; Staroverov, V. N.; Keith, T.; Kobayashi, R.; Normand, J.; Raghavachari, K.; Rendell, A.; Burant, J. C.; Iyengar, S. S.; Tomasi, J.; Cossi, M.; Rega, N.; Millam, J. M.; Klene, M.; Knox, J. E.; Cross, J. B.; Bakken, V.; Adamo, C.; Jaramillo, J.; Gomperts, R.; Stratmann, R. E.; Yazyev, O.; Austin, A. J.; Cammi, R.; Pomelli, C.; Ochterski, J. W.; Martin, R. L.; Morokuma, K.; Zakrzewski, V. G.; Voth, G. A.; Salvador, P.; Dannenberg, J. J.; Dapprich, S.; Daniels, A. D.; Farkas, O.; Foresman, J. B.; Ortiz, J. V.; Cioslowski, J.; Fox, D. J. Gaussian, Inc., Wallingford CT, 2010. 
17. In compounds wherein the heavier halogens form a covalent bond, there is a region of higher electron density, where the electrostatic potential is negative, and also a region of lower electron density ( $\sigma$-hole), where the potential is positive. The positive potential generates a cap of depleted electron density and results in attractive interactions with electron-rich sites. The halogen, therefore, can act as both an electron-rich and an electron-deficient center. See: (a) Cavallo, G.; Metrangolo, P.; Milani, R.; Pilati, T.; Priimagi, A.; Resnati, G.; Terraneo, G. The Halogen Bond. Chem. Rev. 2016, 116, 2478-2601. (b) Alkorta I.; Rozas, I.; Elguero, J. Non-conventional hydrogen bonds. Chem. Soc. Rev. 1998, $27,163-170$.

18. Hoffmann, R.; Woodward, R. B. Orbital Symmetries and endo-exo Relationships in Concerted Cycloaddition Reactions. J. Am. Chem. Soc. 1965, 87, 4388-4389.

19. (a) Matzner, E.; Apeloig, Y. Evidence for the Dominant Role of Secondary Orbital Interactions in Determining the Stereochemistry of the Diels-Alder Reaction: The Case of Cyclopropene. J. Am. Chem. Soc. 1995, 117, 5375-5376. (b) Sodupe, M.; Rios, Raphael; Branchadell, V.; Nicholas, T.; Oliva, A.; Dannenberg, J. J. A Theoretical Study of the Endo/Exo Selectivity of the Diels-Alder Reaction between Cyclopropene and Butadiene. J. Am. Chem. Soc. 1997, 119, 4232-4238. (c) Wannere, C. S.; Paul, A.; Herges, R.; Houk, K. N.; Schaefer, H. F., III; Schleyer, P. v. R. The existence of secondary orbital interactions. J. Comput. Chem. 2007, 28, 344-361. (d) Fernandez, I.; Bickelhaupt, F. M. Origin of the "endo rule" in Diels-Alder reactions. J. Comput. Chem. 2014, 35, 371-376.

20. (a) Arrhenius, S. A. Über die Dissociationswärme und den Einfluss der Temperatur auf den Dissociationsgrad der Elektrolyte. Z. Phys. Chem. 1889, 4, 96-116. (b) Arrhenius, S. A. Über die Reaktionsgeschwindigkeit bei der Inversion von Rohrzucker durch Säuren. Z. Phys. Chem. 1989, 4, 226248. 


\section{Table of Contents}

The endo/exo stereoselectivity of the Diels-Alder reaction of cyclopentadiene with substituted cyclopropenes is generally different from that of butadiene. Also, calculations at different levels of theory fail to predict the experimental selectivity of halogen-substituted cyclopropenes in reactions with cyclopentadiene.

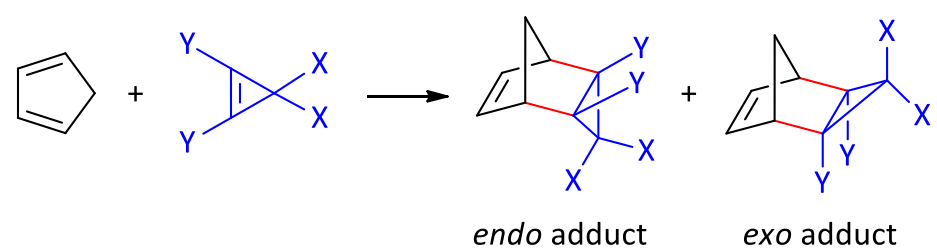

